\title{
La colisión entre la justicia comunal y la justicia ordinaria, en el delito de tenencia ilegal de armas de fuego en la etnia Awajún
}

\section{The collision between communal justice and ordinary justice, in the crime of illegal possession of firearms in the Awajun ethnic group}

Bardales del Aguila, Lionel 1[0000-0002-9110-4475]

${ }^{1}$ Universidad Nacional de San Martín, Tarapoto, Perú lbardales@unsm.edu.pe

Resumen. El estudio tiene como propósito analizar la colisión de la justicia comunal entre la etnia Awajún y la justicia ordinaria, el mismo se desarrolla en la provincia de Rioja, región San Martín. La investigación es de tipo aplicada y descriptiva, la población y muestra de estudio la conformaron 458 pobladores Awajun, a quienes se les aplicó una encuesta; se entrevistó a cinco Apus (Jefes) de las comunidades nativas y a siete autoridades vinculadas con la justicia ordinaria, asimismo; se analizaron expedientes y sentencias aplicadas sobre el tema vinculado al derecho penal positivo y la aplicación de la eximente sobre error culturalmente condicionado en el caso A1. Los resultados indican: Que el $91 \%$ de los pobladores Awajún utilizan armas de fuego con fines de caza y seguridad, formando parte de su costumbre y tradición. Los Apus, afirman que los pobladores no conocen los procedimientos sobre el registro de armas de fuego. El 96\% de pobladores prefiere la justicia comunal y el $70 \%$ cree que la tenencia de armas de fuego debe resolverlo la justicia indígena. En conclusión, pese a los esfuerzos de las autoridades judiciales de la región San Martín por establecer políticas de coordinación entre ambos sistemas de justicia; las contradicciones y conflictos persisten, motivados generalmente por la prevalencia del monismo jurídico y la concepción positivista de los operadores de justicia.

Palabras clave: Error culturalmente condicionado, justicia comunal, justicia ordinaria, tenencia ilegal de armas de fuego

Citar como: Bardales del Aguila, L. (2021). La colisión entre la justicia comunal y la justicia ordinaria, en el delito de tenencia ilegal de armas de fuego en la etnia Awajún. Revista Científica Ratio Iure, 1(2), 4-37. https://doi.org/10.51252/rc ri.v1i2.195

Recibido: $10 / 03 / 2021$

Aceptado: 11/06/2021

Publicado: 28/07/2021

\begin{abstract}
The purpose of the study is to analyze the collision of communal justice in the Awajún ethnic group and ordinary justice, it is developed in the province of Rioja, San Martín region. The re-search is of an applied and descriptive type, the population and study sample were made up of 458 Awajún residents, to whom a survey was applied; Five Apus (Chiefs) of the native communities and seven authorities linked to the ordinary justice were also interviewed; Files and judgments applied on the subject related to positive criminal law and the application of the defense on culturally conditioned error in case A1 were analyzed. The results indicate: That $91 \%$ of the Awajún inhabitants use firearms for hunting and security purposes, forming part of their custom and tradition. The Apus or Chiefs, affirm that the inhabitants do not know the procedures on the registration of firearms. $96 \%$ of residents prefer communal justice and $70 \%$ believe that the possession of firearms should be resolved by indigenous justice. In conclusion, despite the efforts of the judicial authorities of the San Martín region to establish coordination policies between both justice systems; contradictions and conflicts persist, generally motivated by the prevalence of legal monism and the positivist conception of justice operators.

Keywords: Communal justice, culturally conditioned error, illegal possession of firearms, ordinary justice
\end{abstract}




\section{Introducción}

Ante el avance de la ola delictiva en el Perú; el Estado peruano viene endureciendo la política criminal; como en el tipo de tenencia ilegal de armas de fuego; por otro lado, la construcción de carreteras ha incrementado la ola migratoria de "colonos" en el ámbito territorial de los pueblos originarios de la región San Martín, violentado los usos y costumbres tradicionales. La implantación del sistema jurídico ordinario ha colisionado con el sistema de justicia comunal, produciéndose conflictos entre las organizaciones indígenas y los operadores de la justicia estatal, que en su afán de reprimir las conductas delictivas se ven enfrentadas con las comunidades nativas.

En Argentina, la jurisprudencia resalta dos casos de aplicación de justicia con criterio intercultural: El Caso F1 y el J2, el primero sobre delito de lesiones graves, entre miembros de la comunidad indígena Mapuche ya que, en ocasión de una discusión, se había herido al joven V1, mediante un disparo de arma de fuego provocándole la pérdida de la visión en un ojo.

El segundo caso, sobre delito de violación sexual de una menor indígena perteneciente al pueblo Wichí, fue resuelto por la Suprema Corte de Justicia de Salta; con la sentencia del imputado en primera instancia; la defensa recurre a casación sustentando que el fallo vulnera normas constitucionales al no respetar las costumbres y normas imperantes en el pueblo Wichí. La Corte Resuelve declarar fundada la demanda de casación absolviéndose al imputado por considerar que el hecho se desarrolló en el contexto de convivencia del imputado y de la víctima en un marco de costumbre ancestrales y los Arts. 75 inc. 17 de la Constitución nacional y 15 de la Constitución Provincial que garantizan el respeto a la identidad de los pueblos indígenas.

El Informe del Ministerio de Justicia y Derechos Humanos sobre la administración de justicia con enfoque intercultural en las regiones: Lorero, Ucayali, Amazonas y San Martín. En el caso de San Martín, reporta la atención de 49 casos, de pobladores indígenas Awajún sentenciados por diferentes tipos de delitos, entre los que se destacan: Violación sexual (11 casos), homicidio (8 casos), Contra los bosques o formación boscosa (4 casos), Secuestro con subsecuente muerte, Narcotráfico y Tráfico ilícito de drogas, Conducción en estado de ebriedad, Tenencia ilegal de armas, Coacción; con dos casos cada uno; y Lesiones seguidas de muerte, Robo agravado, Actos contra el pudor, Usurpación, Peculado y Estafa con 1 caso cada uno. Encontrándose sentenciados 8 casos, procesados 11 , archivados 8 ; e investigados 2 casos.

En Perú, Francia e Yrigoyen (2008) estudiaron sentencias que hacen referencia a casos en que la administración de justicia ordinaria tuvo que mediar con delitos cometidos por pobladores de origen indígena entre las que tenemos: 
El Exp. No 97-0061 - 191601 - SP - 01; (Distrito Judicial de Loreto, 1999), sobre relaciones sexuales con una menor de 13 años, entre ribereños con costumbres y concepciones de familia distintos a la sociedad occidental. Sin embargo, no se aplica el eximente, sino el atenuante de pena (Pena de 10 años y tratamiento terapéutico). El Exp. № 98-175, (Sala Penal de Loreto 1999); Caso de "rapto" de menor de 8 años sin consentimiento de sus padres y con ocultamiento de las autoridades de la comunidad nativa. El Tribunal aplica atenuante por cultura. Falla declarando al acusado S1, culpable.

El Exp. No. 98-00320-010104JP01- (Distrito Judicial de Amazonas), sobre profesor de comunidad nativa tiene relaciones con menor de su misma comunidad, aprovechando que ella era huérfana y se encontraba desamparada. Después de ser denunciado, se casa con la menor. Se le aplica atenuante por cultura.

El Exp. No 00-0492-191601-SP-03/EXP. 492-00-Distrito Judicial de Loreto, que resuelve con prisión preventiva en contra del imputado T1 por el delito de Homicidio Simple, en agravio de E2, por "brujo malo".

La Sentencia de la Sala Penal Permanente de la Corte Suprema de Justicia (R. N. 3598-2003 Cono Norte de Lima, 2004) por violación sexual en el que señala "Que el imputado es natural del Distrito de Margos, Provincia de Ambo departamento de Huánuco pero vino a radicar a Lima desde hace más de tres años antes de ocurridos los hechos; considera que el imputado actuó como lo hizo en función a su procedencia cultural, afirmando que en el ámbito geográfico cultural del que es oriundo el imputado los jóvenes se unen sexualmente a muy temprana edad...por lo que falla eximiéndole de la responsabilidad por tratarse de un error de tipo invencible.

En la región San Martín, Yrigoyen (2008) estudia la sentencia de la Corte Suprema del Perú del 09 de junio de 2004, que en aplicación del artículo $149^{\circ}$ de la Constitución, falla absolviendo a los ronderos de Moyobamba por los delitos de secuestro y otros, revocando la sentencia de la Sala Penal de Moyobamba; que condenó a los ronderos a tres años de prisión efectiva por los delitos mencionados, así como a pagar reparación civil a los presuntos agraviados (los asaltantes a quienes las rondas habían aplicado cadena ronderil).

La investigación se ubica en la provincia de Rioja y comprende a las comunidades nativas de: Shampuyacu, con sus anexos Kunchum y Tumbaro, Alto Naranjillo, Alto Mayo con su anexo Huasta, Bajo Naranjillo y San Juan de Río Soritor; para lo cual se solicitó la autorización al Presidente de la Federación Regional Indígena Awajún del Alto Mayo (FERIAAM), al Presidente de la Corte superior de Justicia de San Martín, al Director Regional de la Policía Nacional del Perú.

La investigación se justifica porque se ha observado conflictos entre las comunidades nativas y las autoridades del Ministerio Público, Policía Nacional y Poder Judicial, en el tema específico 
de la tenencia ilegal de armas de fuego; tipificado en el Artículo 279 del Código Penal peruano como delito contra la seguridad pública y la Ley N 30229 que reprime con la pena privativa de libertad "no menor de seis ni mayor de quince años"

Tal es así, que, en el Alto Mayo, región San Martín se reportaron casos de pobladores nativos Awajún intervenidos por la Policía Nacional por el delito de tenencia ilegal de armas de fuego, como los reportados por el Diario "Ahora" en el que fueron intervenidos N1 (31), N2 (47), N3 de (48), N4 de (21) y N5 de (40); todos puestos a disposición de la Fiscalía para el proceso correspondiente.

Se analizó el caso A1 procesado por el delito contra la seguridad pública, peligro común en la modalidad de tenencia ilegal de arma de fuego, donde el Ministerio Público a través de la Resolución $N^{\circ}$ Tres, Nueva Cajamarca, Catorce de enero de 2014; dicta auto de enjuiciamiento en contra de A1 como autor del delito contra la seguridad pública peligro común en la modalidad de tenencia ilegal de armas de fuego delito previsto en el artículo 279 del Código Penal, en agravio del Estado Peruano-Ministerio del Interior, imponiéndosele una pena de cuatro años de pena privativa de libertad y al pago de una Reparación Civil de setecientos nuevos soles (S/. 700.00).

Ante esta situación se formuló la siguiente pregunta de investigación: ¿Cuáles son los factores que determinan la colisión de la administración de justicia comunal con la administración ordinaria en relación al delito contra la seguridad pública en la modalidad de tenencia ilegal de armas de fuego en la etnia Awajun de la provincia de Rioja, región San Martín?

\subsection{Objetivo General:}

Determinar los factores que inciden en la colisión de la administración de justicia comunal con la administración ordinaria en el delito contra la seguridad pública en la modalidad de tenencia ilegal de armas; la etnia Awajun de la provincia de Rioja, región San Martín.

\subsection{Objetivos Específicos:}

- Identificar las formas de administración justicia comunitaria y ordinaria en relación a su efectividad, celeridad y aceptabilidad.

- Analizar los tipos de delitos penales cometidos por la población nativa Awajun de Shampuyacu, Alto Naranjillo, Bajo Naranjillo y sus sectores.

- Analizar las normas legales de la justicia ordinaria en relación a las normas consuetudinarias de la justicia comunal de la etnia Awajun.

- Establecer un enfoque intercultural de aplicación coordinada entre la justicia comunal y ordinaria. 
- Determinar los factores claves para la colisión de entre la justicia comunitaria con la administración de justicia ordinaria.

\subsection{Hipótesis General:}

Los factores que determinan la colisión entre la administración de justicia comunitaria y la administración de justicia ordinaria en el tema de la tenencia ilegal de armas tienen que ver con la disfunción entre el derecho positivo ordinario y las costumbres de los pueblos indígenas, la hegemonía y control social y la desconfianza en la justicia ordinaria.

\section{Materiales y Métodos}

Para el estudio se tuvo en cuenta el análisis del Expediente $\mathrm{N}^{\circ}$ 005-2014-PE-JUNC, y el Exp. $\mathrm{N}^{\circ}$ 100-2013-02- 2208-JR-PE; sobre tenencia ilegal de armas de fuego; asimismo la jurisprudencia sobre fallos de casos seguidos contra pobladores nativos en otras jurisdicciones, y se revisó la literatura pertinente y el marco jurídico sobre este tipo penal.

\subsection{Tipo y Métodos de Investigación:}

La investigación es de tipo aplicada, nivel descriptivo, diseño de investigación no experimental; metodología cuantitativa y cualitativa, con estudio documental y de campo. Se aplicó una encuesta a los pobladores Awajun y una entrevista grabada con filmadora a los Apus de las Comunidades Nativas y a los operadores del sistema de justicia ordinario.

La población de estudio estuvo conformada por 1167 pobladores hombres y mujeres de 18 a 65 años de edad, aplicándose el muestreo probabilístico, se obtuvo una muestra de 458 pobladores, que representa el $39,16 \%$ de pobladores distribuidos en las 8 comunidades. A quienes se aplicó una encuesta de 12 ítems.

Se entrevistó a 5 jefes de Comunidades Nativas, a la Jueza de Paz No Letrada y Gobernador del Distrito de Awajun, a los Comisarios de la PNP de Naranjos (Distrito de Pardo Miguel) y de Nueva Cajamarca; al Juez en lo Penal de Nueva Cajamarca, a la Directora de la Defensa Publica del Ministerio Publico y al Presidente de la Corte Superior de Justicia de San Martín. 


\section{Resultados y discusiones}

Tabla 1

¿Qué tipos de conflictos y problemas se presentan en la comunidad?

\begin{tabular}{llll}
\hline $\mathbf{N}^{\circ}$ & Tipos de conflictos & f & $\%$ \\
\hline $\mathbf{1}$ & Peleas y ataques entre comuneros & 353 & 77,1 \\
$\mathbf{2}$ & Robo y hurto & 67 & 14,6 \\
$\mathbf{3}$ & Asalto & 6 & 1,3 \\
$\mathbf{4}$ & Violación & 4 & 0,9 \\
$\mathbf{5}$ & Con los colonos por ocupación de tierras & 12 & 2,6 \\
$\mathbf{6}$ & Por caza y tala en territorio comunal & 2 & 0,4 \\
$\mathbf{7}$ & Con la PNP y Fiscalía & 3 & 0,7 \\
$\mathbf{8}$ & Con el Poder judicial & 1 & 0,2 \\
$\mathbf{9}$ & Otro: Asesinato, brujería, violencia familiar & 10 & 2,2 \\
\hline & Total & 458 & 100
\end{tabular}

La tabla 1, muestra que el $77,1 \%$ de pobladores; reconocen como los conflictos y problemas más frecuentes; las peleas y ataques entre comuneros; el 14,6\%, el robo y hurto, el 2,6\%, con los colonos por ocupación de tierras, el 0,9\% señalan la violación; el 0,4\% por caza y tala en territorio comunal; el 0,7\% con la Policía Nacional y la Fiscalía, el 0,2\%; con el Poder Judicial. En la categoría de otros, 10 pobladores que representan el 2,2\% mencionan el asesinato, la brujería y violencia familiar.

Obsérvese que, el tercer conflicto incidente es por la ocupación de tierras por parte de los colonos y el 0,9\% manifiesta conflictos con la PNP, la Fiscalía y el Poder Judicial.

La tabla 2, sobre a dónde recurren para obtener justicia; el 95,6 \% recurren al Apu de la comunidad, el 1,9\% a la Asamblea Comunal, el 1,1\% al Juzgado de Paz no Letrado; el 0,4\% de a la PNP; el 0,7\% a la Fiscalía Provincial, y el 0,3\% de pobladores expresan no haber recurrido a ninguna de estas instituciones para resolver su problema.

De ello, se infiere que la población Awajun tiene mayor confianza en la justicia comunal, entre la PNP y la Fiscalía Provincial, optan por esta última. 
Tabla 2

Tipo de denuncias y casos en las que participaron pobladores nativos.

\begin{tabular}{rlcr}
\multicolumn{1}{c}{ Tipo de casos } & $\mathbf{f}$ & $\mathbf{\%}$ \\
\hline $\mathbf{1}$ & Asalto y robo & 61 & 39,6 \\
$\mathbf{2}$ & Asesinato & 43 & 27,9 \\
$\mathbf{3}$ & Violación & 33 & 21,4 \\
$\mathbf{4}$ & Agresión física & 6 & 3,8 \\
$\mathbf{5}$ & Tala y caza ilegal & 1 & 0,6 \\
$\mathbf{6}$ & Invasión de propiedad & 1 & 0,6 \\
$\mathbf{7}$ & Tenencia ilegal de armas de fuego & 22 & 14,2 \\
$\mathbf{8}$ & Conducción en estado de ebriedad & 2 & 1,2 \\
$\mathbf{9}$ & Otro & 8 & 5,1 \\
\hline
\end{tabular}

En esta tabla se observa, que el caso de mayor incidencia es el de asalto y robo con el 39,6\%, en segundo lugar, el asesinato con el 27,9\%; en tercer lugar, la violación, con 21,4\%: en cuarto lugar la tenencia ilegal de armas de fuego con el 14,2\%; la agresión física el 3,8\%, Conducción en estado de ebriedad el 1,2\%; la tala ilegal e invasión a la propiedad, representan el 0,6\%; y en el rubro de otro no precisado aparecen 8 casos, representando el 5,1\%.

Tabla 3

¿Utilizar arma de fuego forma parte de tu costumbre, tradición y seguridad comunal?

\begin{tabular}{cccccc}
\hline \multirow{2}{*}{$\begin{array}{c}\text { Escalas de } \\
\text { medición } \\
\text { variable uno }\end{array}$} & \multicolumn{2}{c}{$\begin{array}{c}\text { Intervalo de } \\
\text { clase }\end{array}$} & \multirow{2}{*}{ Fi } & Hi & \% \\
\cline { 2 - 4 } & inferior & $\begin{array}{c}\text { Limite } \\
\text { súper }\end{array}$ & & & \\
\hline Inadecuado & 16 & 27 & 8 & 0.2 & $20 \%$ \\
\hline Regular & 28 & 39 & 19 & 0.475 & $48 \%$ \\
\hline Adecuado & 40 & 51 & 13 & 0.325 & $33 \%$ \\
\hline & Total & & 40 & 1 & $100 \%$ \\
\hline
\end{tabular}

El $84 \%$ de los comuneros menciona que el uso del arma de fuego forma parte de su tradición, costumbre y seguridad personal, el 16\% respondieron no. Ello evidencia, que la población nativa usa el arma de fuego; sea escopeta, trampero hechizo con fines de subsistencia y seguridad personales.

\section{Tabla 5}

¿Cómo adquiriste el arma de fuego?

\begin{tabular}{llrc}
\hline $\mathbf{N}^{\circ}$ & Adquisición del arma de fuego & $\mathbf{f}$ & $\boldsymbol{\%}$ \\
\hline $\mathbf{1}$ & Lo presto & 37 & 8 \\
$\mathbf{2}$ & Lo compro & 366 & 80 \\
$\mathbf{3}$ & Lo heredé de mis padres & 43 & 9 \\
$\mathbf{4}$ & Otro $\quad 12$ & 3 \\
\hline \multicolumn{2}{c}{ Total } & 458 & 100
\end{tabular}

Los resultados muestran que el $80 \%$ de los comuneros adquirieron las armas de fuego a través de la compra, el 9\%, que representa lo heredaron de sus padres; el $8 \%$ indica que lo prestan; y el 3\% de los encuestados lo consiguen de otro modo, no precisado en forma específica. Esto evidencia 
la tenencia o posesión de armas de fuego de procedencia dudosa, que pondría en riesgo la situación legal de los comuneros.

\section{Tabla 6}

¿Cuál de los dos tipos de justicia resuelve mejor los problemas?

\begin{tabular}{clcc}
\hline $\mathbf{N}^{\circ}$ & $\begin{array}{l}\text { ¿Cuál de los tipos de justicia resuelve mejor } \\
\text { los problemas? }\end{array}$ & $\mathbf{f}$ & $\mathbf{\%}$ \\
\hline $\mathbf{1}$ & La justicia comunal & 326 & 71,2 \\
$\mathbf{2}$ & La justicia ordinaria & 132 & 28,8 \\
\hline & Total & 458 & 100
\end{tabular}

El $71,2 \%$ de los pobladores encuestados manifiestan que la justicia comunal resuelve mejor los problemas; el $28,8 \%$, indican preferir la justicia ordinaria.

Tabla 7

¿Cómo calificas a la justicia ordinaria?

\begin{tabular}{llcc}
\hline $\mathbf{N}^{\circ}$ & Respuesta & $\mathbf{f}$ & \% \\
\hline $\mathbf{1}$ & Mala & 65 & 14,2 \\
$\mathbf{2}$ & Regular & 254 & 55,5 \\
$\mathbf{3}$ & Buena & 139 & 30,3 \\
\hline & Total & 458 & 100
\end{tabular}

El 55,5\% de los encuestados califican a la Justicia Ordinaria como regular, 30,3\% como buena, el $14,2 \%$ afirman que es mala. De ello se infiere, que la población Awajún, manifiesta su baja valoración a la justicia ordinaria.

Tabla 8

¿Estás de acuerdo contar con un Concejo Mayor de Justicia Comunal?

\begin{tabular}{clrl}
\hline $\mathbf{N}^{\circ}$ & Respuesta & f & \% \\
\hline $\mathbf{1}$ & $\mathrm{Si}$ & 391 & 71,45 \\
$\mathbf{2}$ & No & 67 & 28,9 \\
\hline & Total & 458 & 100 \\
\hline
\end{tabular}

El 71,45 de los encuestados, indican que están de acuerdo en contar con un Consejo de Mayor de Justicia Comunal; el 28,9\%, expresan no estar de acuerdo.

Esta posición de los pobladores refleja el interés por profundizar el nivel de decisión y de la justicia comunal Awajún.

\subsection{Resultados de las entrevistas aplicadas a Jefes de las Comunidades Nativas y al Presidente de la Federación Regional Indígena Awajún del Alto Mayo - FERIAAM.}

Pregunta 1: ¿Qué tipos de conflictos y problemas se presentan en la comunidad?

En relación a esta pregunta, los Apus de las Comunidades Reynaldo Tuwits Ampam, Apu de la comunidad nativa de Alto Naranjillo, Tomas Wajajai Tuwits, Apu de la comunidad nativa de 
Shampuyacu, Manuel Juep Kawaza, Apu de la comunidad Nativa de Bajo Naranjillo, Moises Asagkay Wajay, Apu de la comunidad nativa Awajún Alto Mayo; manifestaron:

- "No tenemos muchos problemas; Antes se han presentado crímenes, ahora hay peleas, robos: En caso de peleas y robos; aplicamos la justicia comunal.

- "Hay casos de robos, asaltos... En caso de nativo con nativo se soluciona acá de buena fe ... Hubo un caso de comuneros que se fueron a Naranjos; fueron detenidos por la Policía de Carreteras en aguas Verdes, con armas que fueron decomisadas a colonos en el bosque de protección; se encuentran procesados. Dichas armas no son de propiedad de los comuneros, sino armas encontradas a otras personas".

- Manuel Juep Kawaza, recalca: "Existen diversos tipos de problemas, uno de ellos es la brujería; como creencia de hacer algún daño o mal a alguien, la infidelidad; cuando un hombre o una mujer saca la vuelta o traiciona a su esposa"

- Moises Asagkay Wajay: "Si tenemos problemas sociales, como problemas de hogares, nos ha sucedido también matanzas y también uso de pistolas para defensa personal sin licencia. Pero se ha solucionado de acuerdo a nuestras costumbres"

- Mariano Entsakua Sutam, Presidente de la FERIAAM: "Si, hay robos, adulterio; se presentan nuevos problemas como: invasión de territorios y por arriendos de terrenos y chacras. En este caso, Ministerio de agricultura, entrega tierras, sabiendo que las comunidades nativas tienen los títulos de la comunidad, los invasores dicen, que son terrenos libres"

Pregunta 2: ¿En casos de peleas y riñas entre comuneros; recurren a usted en busca de solución? Los Apus de las comunidades nativas coinciden en responder que dentro del ámbito de la comunidad se sanciona y castiga a los denunciados de acuerdo a la gravedad de la falta se aplica el Estatuto.

- Tomas Wajajai Tuwits, Apu de la comunidad nativa de Shampuyacu, recalca “... En caso de peleas entre comuneros, lo calaboceamos, los aconsejamos y sacamos. En caso de robos, asaltos y uso de armas, analizamos de dónde es; si es de nuestra comunidad, lo metemos al calabozo, comunicamos a sus familiares, en presencia de los miembros ancianos entonces se hace pagar la reparación civil. Si esto no se cumple pasamos a la Fiscalía".

- Manuel Juep Kawaza, Apu de la comunidad Nativa de Bajo Naranjillo, menciona sobre la brujería e infidelidad: "En caso de brujería, antiguamente se arreglaba a través de la venganza, se mataban entre ellos; hoy día se llama a las familias y se busca llegar a un 
acuerdo. En el caso de infidelidad, se aplica un castigo de 72 horas de calabozo y trabajo de limpieza comunal"

- Moises Asagkay Wajay, Apu de la comunidad nativa Awajún Alto Mayo, indica: “... contamos un estatuto, aprobado por las 14 comunidades nativas dentro de ese estatuto hay un orden como aplicar y castigar si uno comete error. Si una persona comete adulterio, robo o menosprecio de acuerdo a su gravedad ... Analizamos de dónde es; si es de nuestra comunidad, lo metemos al calabozo, comunicamos a sus familiares, en presencia de los miembros ancianos entonces se hace pagar la reparación civil. Si esto no se cumple pasamos a la fiscalía"

- Mariano Entsakua Sutam, Presidente de la FERIAAM, reitera: "Los casos se resuelven de acuerdo a la gravedad, los casos que no pueden resolverse en la comunidad, lo resuelve la FERIAAM. Otros, lo resuelve el Juzgado de Paz. Entre ellos tenemos el adulterio y el robo" ... Se aplica el reglamento interno de la comunidad, en caso de adulterio se castiga con separación de la comunidad hasta por tres meses, para el hombre... En caso de robo, se obliga al culpable a devolver lo robado, a realizar trabajos y a comprometerse a no volver a robar"

Pregunta 3: ¿Conoces de alguna denuncia presentada contra algún morador ante la justicia ordinaria?

Los Apus de las Comunidades mencionan conocer varios casos en los que pobla-dores Awajún fueron intervenidos por la Policía Nacional y la Fiscalía.

- Tomas Wajajai Tuwits, Apu de la comunidad nativa de Shampuyacu; destaca los casos del Apu que fue condenado a prisión por ocho años “... en Bajo Naranjillo hubo una persona que había muerto, fue amarrado a una tangarana y se murió, el Apu fue mandado a la cárcel por ocho años. Esto pasó en caso de nativo con mestizo. En caso de nativo con nativo se soluciona acá de buena fe"... hubo un caso de comuneros que fueron detenidos por la Policía de Carreteras en Aguas Verdes, con armas que fueron decomisadas a colonos en el bosque de protección; se encuentran procesados. Dichas armas no son de propiedad de los comuneros, sino armas encontradas a otras personas.

- Manuel Juep Kawaza, Apu de la comunidad Nativa de Bajo Naranjillo, afirma conocer que “...varias veces los comuneros fueron intervenidos por la Policía y la Fiscalía de Nueva Cajamarca... Como en el caso de dos menores, que robaron plata de su abuelo, el Apu de la comunidad los castigó en el calabozo... la madre acudió a la Fiscalía y Policía ellos intervinieron en contra del Apu de la comunidad"

- Moises Asagkay Wajay, Apu de la comunidad nativa Awajún Alto Mayo, recuerda: "Una vez se detuvo a ex Apu de Comunidad. Por atender la denuncia de un mestizo, incautaron 
100 quintales de café, por deuda. El caso pasó a la justicia ordinaria, con abogados. Fue detenido. En ese caso ya no puede intervenir la justicia comunal. No había robo, para nosotros se retuvo el café, para obligar el pago de la deuda. Él pensó hacer justicia comunal, pero fue injusticia en justicia ordinaria... no había robo".

- El Presidente de la FERIAAM, Mariano Entsakua Sutam, reitera “...Tenemos conocimiento que en la cárcel de Moyobamba tenemos 35 nativos sentenciados por diferentes tipos de delitos, ellos ya están sentenciados; por robo, violación, asalto, drogas y asesinato... "hoy día la población se ha mezclado con otros, por amistades, se contagian y cometen robos, violación, uso de drogas y hasta siembra de drogas"

Pregunta 4: ¿Conoces el caso de algún comunero que haya sido procesado en la justicia ordinaria por tenencia ilegal de armas de fuego?

Todos los Apus de las comunidades mencionan conocer sobre pobladores Awajun intervenidos por la Policía Nacional por portar armas de fuego.

- Reynaldo Tuwits Ampam, Apu de la comunidad nativa de Alto Naranjillo: "Si conozco, la mayoría tiene, licencia... pero los que compran de segunda tienen problema, eso debe resolverse. Hubo Casos que la Policía ha intervenido a comuneros, nosotros hemos acudido, nosotros comuneros no tenemos armas pesada, solo usamos armas de caza"

- Manuel Juep Kawaza, Apu de la comunidad Nativa de Bajo Naranjillo: "Varias veces, los comuneros fueron intervenidos por la Policía Nacional por uso de armas de fuego. Por no tener licencia. La mayoría de la población, el 35\% debe tener una escopeta. Lo usan para la chacra, con fines personales y caza de animales. Para un comunero no es delito portar un arma de fuego. Cuando la Policía interviene el caso se va a la justicia ordinaria"

- Moises Asagkay Wajay, Apu de la comunidad nativa Awajún Alto Mayo: "Si un caso... Antes se daba más casos, hoy se ha frenado porque se ha puesto en cono-cimiento de todos para no comprar armas de segunda o por vendedores desconocidos. Hemos intervenido para solucionar. Los comuneros sólo usan armas de calibre 16 (escopetas) para la caza, para nosotros no es ilegal, en caso de otro tipo de ar-mas, acordamos transferirlo a la justicia ordinaria. Ya hemos prohibido la compra de otro tipo de armas"

- Mariano Entsakua Sutam, Presidente de la FERIAAM: “...conocemos de pobladores que se encuentran procesados, están esperando se resuelva su caso. Los nativos usan armas de fuego, escopetas para la caza, no usan otros tipos de armas. En caso de otro tipo de armas, pistolas, revólveres u otros deben ser investigados por la justicia ordinaria. La justicia comunal debe ver los casos de uso de escopetas". 
Pregunta 5: ¿Conoces que para la tenencia y uso de armas de fuego deben contar con tarjeta de propiedad y licencia para su uso?

Todos los Apus de las comunidades nativas y el Presidente de la FERIAAM, manifiestan tener conocimiento sobre la necesidad de contar con el registro y licencia para portar armas de fuego.

- Reynaldo Tuwits Ampam, Apu de la comunidad nativa de Alto Naranjillo, indica: “...Para mí el portar un arma de fuego (escopeta o retrocarga) sin licencia no es delito, no usamos el arma para cualquier cosa, sino sólo para caza".

- Tomas Wajajai Tuwits, Apu de la comunidad nativa de Shampuyacu: “...Para nosotros tener una escopeta no es un delito. Acá en Shampuyacu, algunos tendrán, no tenemos muchas armas, muchas veces lo prestan. El estatuto de nosotros, da el uso libre de armas ...no es ilegal el uso de armas, en caso de que quieran tener debe sacar su licencia”

- Manuel Juep Kawaza, Apu de la comunidad Nativa de Bajo Naranjillo: “...Para un comunero no es delito portar un arma de fuego. Cuando la Policía interviene el caso se va a la justicia ordinaria".

- Moises Asagkay Wajay, Apu de la comunidad nativa Awajún Alto Mayo: "Los comuneros sólo usan armas de calibre 16 (escopetas) para la caza, para nosotros no es ilegal, en caso de otro tipo de armas, acordamos transferirlo a la justicia ordinaria. Ya hemos prohibido la compra de otro tipo de armas"

- Mariano Entsakua Sutam, Presidente de la FERIAAM: "Los nativos usan armas de fuego, escopetas para la caza, no usan otros tipos de armas. En caso de otro tipo de armas, pistolas, revólveres u otros deben ser investigados por la justicia ordinaria.

Pregunta 6: ¿Conoces que para la tenencia y uso de armas de fuego deben contar con tarjeta de propiedad y licencia para su uso?

Todos los jefes de las comunidades nativas, coinciden en indicar que tienen cono-cimiento de dichos requisitos; pero que, el mismo es desconocido por la mayoría de comuneros, al tratarse de armas de fuego para la caza y subsistencia como las escopetas retrocargas o tramperos no es necesario, salvo que se trate de otro tipo de armas.

Pregunta 7: ¿Dónde crees, deben ser procesados los comuneros denunciados por tenencia ilegal de armas de fuego?

Todos los jefes comunales y el Presidente de la FERIAAM; coincidieron al señalar de que la tenencia de arma de fuego (retrocarga, escopeta o trampero) no constituye delito; en el caso de 
ser intervenidos por las autoridades policiales, bastaría el testimonio de los jefes de la comunidad para resolver el caso... "El caso de los comuneros intervenidos con posesión de armas de fuego debe ser tratado en la comunidad. La Policía Nacional debería consultar con el Apu de la comunidad. La justicia comunal es más rápida, conoce al comunero".

- Mariano Entsakua Sutam, Presidente de la FERIAAM, reitera: "La justicia comunal debe ver los casos de uso de escopetas", en caso de otro tipo de armas debe intervenir la justicia ordinaria.

Pregunta 8: ¿Cómo calificas a la justicia ordinaria?

- Reynaldo Tuwits Ampam, Apu de la comunidad nativa de Alto Naranjillo: "La justicia ordinaria está en un punto neutro ni bueno ni mala. A veces "el inocente es más culpable", por ejemplo, en el caso de un crimen, que es lo que pasa, en vez de que vaya el criminal, se va el inocente, porque no tiene plata..."

- Tomas Wajajai Tuwits, Apu de la comunidad nativa de Shampuyacu: "Desde el punto de vista de nosotros la justicia ordinaria demora, el problema es que la justicia ordinaria mucho se equivoca, a veces una persona ha sido condenada siendo inocente. Podemos calificar como media. Nosotros la Justicia Comunal es rápida, no hay mentalidad de seguir, sino de llegar a una solución conciliar."

- Manuel Juep Kawaza, Apu de la comunidad Nativa de Bajo Naranjillo: "La justicia ordinaria aplica lo que está escrito en el código, la comunidad aplica las costumbres y tradiciones. La Justicia ordinaria, aplica mayores penas y castigos; pero no busca la solución del problema"...

- Moises Asagkay Wajay, Apu de la comunidad nativa Awajún Alto Mayo: "Estaríamos satisfecho si la justicia ordinaria aplica la justicia transparente y en coordinación con la justicia comunal"

- Mariano Entsakua Sutam, Presidente de la FERIAAM: "Cada tipo de justicia tiene su función, creo que la justicia ordinaria debe ver sus casos igual la justicia comunal, ambos pueden ser buenos o malos según el caso" ... "Falta determinar las competencias de cada uno, debemos tener una lista de sanciones y castigos de la justicia comunal y otra de la justicia ordinaria, no existe un acuerdo. En algunos casos la justicia ordinaria es más fuerte y en otros débiles, igual sucede con la justicia comunal"

"Por ejemplo en caso de castigo y sanción a menores, la justicia ordinaria no castiga al niño; acá tenemos un caso en Bajo Naranjillo, el Apu de comunidad fue denunciado ante Fiscalía, por maltrato a niños, en este caso, el abuelo, denunció a su nieto, por robo de dinero. La Comunidad decidió castigar al niño, con calabozo y trabajo. La madre acudió a la fiscalía y policía; quienes 
intervienen en contra del Apu de Comunidad. Convocados el agraviado y los familiares del niño; al final se pretendió aplicar las medidas correccionales de la justicia ordinaria para el caso de menores. Ante lo cual la madre, optó porque se aplique la justicia comunal. La justicia ordinaria no castiga al niño, la justicia comunal sí. Nuestra justicia busca corregir al niño".

"Igual sucedió en caso de asesinato entre miembros de comunidad; la Fiscalía y policía intervino, pero la comunidad se interpuso; indicando que el caso ya se había resuelto en la comunidad, llegando un acuerdo entre los familiares. En este caso la justicia ordinaria, considera que este tipo de justicia es débil. Por lo que debía aplicarse el código penal, asesinato calificado". ...Por eso digo en algunos casos, la justicia comunal y la justicia ordinaria tiene diferentes puntos de vista. Falta analizar, los tipos de sanciones de ambas justicias"

Pregunta 9: ¿Estás de acuerdo en contar con un consejo mayor de justicia comunal autónomo? Los 4 jefes (Apus) de las comunidades entrevistadas y el Presidente de la FERIAAM manifiestan estar de acuerdo con la constitución del Consejo Mayor de Justicia Comunal.

- Mariano Entsakua Sutam, Presidente de la FERIAAM; enfatiza: "Estamos trabajando para la conformación de Consejo Mayor de Justicia comunal de la Región San Martin, este Consejo debe tener mayor competencia que la justicia de las comunidades, para resolver en última instancia los casos que no puedes resolverlo los jefes de las comunidades. No pueden tratar los casos de terrorismo, homicidio calificado y traiciona a la patria... Vamos a gestionar, ante el ministerio de Justicia y Fiscalía de la Nación que los miembros del Consejo Mayor de Justicia comunal, tengan un presupuesto, y reciban comisiones o dietas por parte del Estado. Actualmente la FERIAAM es la última instancia para resolver los casos. Esa función debe asumirla el Consejo Mayor de Justicia comunal".

3.2 Resultados de las entrevistas aplicadas a Autoridades: Jueza de Paz no Letrada, Gobernador distrital de Awajún, Comisarios de PNP, Fiscal en la Penal de Nueva Cajamarca, Directora de la Defensa Pública y Presidente de la Corte Superior de Justicia de San Martín-Moyobamba.

Pregunta 1 y 2: ¿Tiene conocimiento de actos delictivos en el que se encuentren involucrados pobladores de la etnia Awajún? ¿Podría mencionar los casos registra-dos en su entidad?

- Elsa Peas Cahuaza, Jueza de Paz No Letrada y Lenin Samash Kawaza, Gobernador del Distrito de Awajun, manifiestan:

“...Si en el Juzgado de Paz, vemos diferentes casos entre los que tenemos: abandono de hogar, separaciones, violaciones, omisión de alimentos, homicidios, problemas por el arriendo y sub arriendo de terrenos y chacras, que es un problema frecuente" 
“...existen muchos actos delictivos como: Pandillaje juvenil, asaltos y abigeato; en mayor proporción son cometidos por mestizos, debe haber un 5\% de nativos involucrados. El desarrollo ha traído gentes de otros lugares, y con ello nuevos actos delictivos que antes no había..."

- Segundo Campos Huamán Comisario PNP (e) de Naranjos (Distrito Pardo Miguel): "Pardo Miguel tiene dos comunidades nativas; Alto Mayo y Huasta; mayor-mente los comuneros inciden en casos de violación y el problema de alquiler de tierras. Es por su cultura que llevan..."

- Mayor Francisco Rubio Masa, Comisario PNP del Distrito de Nueva Cajamarca: "En la jurisdicción de Nueva Cajamarca tenemos una Comunidad Nativa de San Juan de Río Soritor, hace dos meses se presentó un caso de un homicidio, de tipo pasional, la víctima fue un nativo. Cuando intervenimos con la Fiscalía de turno conforme a los protocolos de ley para realizar la necropsia; el Apu y los comuneros se opusieron e impidieron el levantamiento del cadáver ellos indicaron hacer la justicia por sus propias manos."

- Dr. Julio Heber Santos Góngora; Fisca Provincial Penal Corporativo de Nueva Cajamarca: "Sí, tenemos conocimiento de casos denunciados por "presunto hurto", violación de menores, tenencia de menores y homicidio..."

- Dra. Juana Aylin Quezada Hidalgo, Directora Distrital de la Defensa Publica de San Martín: "Sí, por supuesto; como en todo lugar existen conflictos, en Awajún se presentan lesiones, peleas, hurto, violaciones, violencia familiar y problemas por arrendamiento de terrenos..."

- Dr, Diego Montenegro Muguerza, Presidente de la Corte Superior de Moyo-bamba: “... Delitos observados son los de usurpación de funciones y de secuestro, esto tanto que en nuestro país no se ha desarrollado la justicia comunal como como en Colombia y Bolivia. Es necesario que se dicte la ley de coordinación entre la justicia ordinaria y la justicia comunal. El caso de secuestro considero que no constituye delito, porque las comunidades tienen competencia para aplicar la justicia comunal en su territorio, tal como lo señala el Art. 149 de la Constitución Política “

Pregunta 3: ¿Conoces casos en que las comunidades nativas hayan resuelto sus conflictos a través de la justicia comunal?

- Elsa Peas Cahuaza, Jueza de Paz No Letrada del Distrito de Awajún: "Nosotros aplicamos la justicia comunal de acuerdo al protocolo de justicia intercultural en vigencia, y los usos y costumbres del pueblo. ...El Juzgado de Paz letrado interviene en los casos que no han sido resueltos por los jefes de la comunidad. En la justicia comunal hay tres niveles: Primero se resuelve por acuerdo mutuo entre las familias, si aquí no se logra acuerdos, 
pasan a las jefaturas de las comunidades; si es que persiste el desacuerdo se recurre a la instancia del Juzgado de Paz No Letrado".

- Lenin Samash Kawaza, Gobernador del Distrito de Awajun: Se han visto casos de amenazas, abigeato y asesinato como lo ocurrido en Alto Naranjillo, eso por el año 2008. Este caso fue tratado en la comunidad, porque fue entre nativos de Huasca-yacu. Se llevó al Consejo, donde se llegó al acuerdo entre las familias. Entraban al acuerdo y el agresor pagaba reparación civil, encargándose de la familia.

- Segundo Campos Huamán Comisario PNP (e) de Naranjos (Distrito Pardo Miguel): Si tenemos conocimiento; en caso que ellos soliciten nuestra intervención les brindamos apoyo.

- Mayor Francisco Rubio Masa, Comisario PNP del Distrito de Nueva Cajamar-ca, reitera: “...Normalmente en casos de violación no podemos ingresar a esa comunidad nativa, varias veces intentamos establecer coordinaciones, en todo momento se han opuesto al ingreso a las comunidades, porque ellos hacen la justicia por sus propias manos, como lo establece los convenios internacionales...Todos los casos que se dan en las Comunidades nativas no se han podido intervenir ni la Policía ni el Ministerio Público"

- Dr. Julio Heber Santos Góngora; Fiscal Provincial Penal Corporativo de Nueva Cajamarca, “...En el caso de presunto hurto cometidos por menores, quienes fueron detenidos, castigados y encarcelados por el Apu de la comunidad nativa, produciéndose la violación de los derechos de los niños, los comuneros se opusieron la intervención de la fiscalía...En el caso de homicidio, los nativos se opusieron a la intervención de la policía y la fiscalía, aduciendo que ellos habían resuelto el caso aplicando la justicia comunal. Finalmente accedieron a realizar la necropsia sin retirar el cadáver del lugar. En este caso se trataba de un crimen pasional cometido con arma de fuego escopeta".

“...Tenemos conocimiento en que las comunidades nativas aplican la justicia comunal de acuerdo a sus costumbres; pero no nos comunican, a veces aplican sanciones drásticas o en otros casos son leves...En el caso de hurto de robo agravado cuyas penas van hasta 8 años privativas de libertad, los nativos aplican a veces penas leves o en otros casos son muy drásticos. A veces se exceden, no se respetan los debidos procesos y se vulneran los derechos fundamentales, en el caso de las rondas campesinas es frecuente, que tengan detenidos a personas hasta un mes... La justicia comunal debe resolver los casos civiles y de faltas, pero en caso de delitos como violación sexual u homicidios es competencia de la justicia ordinaria".

- Dra. Juana Aylin Quezada Hidalgo, Directora Distrital de la Defensa Pública de San Martín: "Si tenemos conocimiento y coordinación con la organización Awajún del Alto Mayo; nosotros como Defensa Pública pedimos que se respete la jurisdicción dentro de su territorio... El año 2014; creamos y lanzamos el Protocolo dirigido a funcionarios del 
Ministerio Público, Policía Nacional y Poder Judicial sobre la justicia comunal, en el que se establece los criterios y procedimientos orientados a respetar las costumbres y leyes de las comunidades. Indicando que las comunidades pue-den intervenir en los casos de lesiones leves; en los delitos graves, si debe intervenir la justicia ordinaria; en ambos casos debe haber coordinación y aplicación adecua-da del protocolo".

- Dr. Diego Montenegro Muguerza, Presidente de la Corte Superior de Moyo-bamba: “...En nuestro país la justicia comunal o comunitaria, no ha sancionado delitos graves, pero si resuelven delitos menores, este tipo lo resuelven diariamente en las comunidades nativas, esto es muy valioso y debe continuar de esa manera resolviendo los conflictos en las comunidades nativas"

Pregunta 4: ¿Conoces el caso de algún comunero que haya sido procesado por tenencia ilegal de armas de fuego?

- Elsa Peas Cahuaza, Jueza de Paz No Letrada y Lenin Samash Kawaza, Gobernador del distrito de Awajún; mencionan: “... En el juzgado de paz no ha visto casos por tenencia ilegal de armas, los pobladores tienen su arma de fuego, escopeta es para la caza de animalitos para su alimentación...Conozco que actualmente hay el caso de un comunero que se encuentra denunciado por tenencia ilegal de armas, el cual se encuentra en proceso en la justicia ordinaria, Fiscalía.

“...Si se han presentados varios casos en Bajo Naranjillo, Shampuyacu y Huasca-yacu. Los comuneros fueron intervenidos por la Policía"

- Segundo Campos Huamán Comisario PNP (e) de Naranjos (Distrito Pardo Miguel): "Se han registrado pocos casos de tenencia ilegal de armas de fuego, porque ellos usan armas de fuego para su caza, el armamento que utilizan son las retrocar-gas y escopetas, no tenemos registrados casos en que los nativos hayan usado su arma de fuego para cometer delitos. ...Han sido intervenidos en la carretera Fernando Belaunde Terry, y puestos a disposición de las autoridades y damos cuenta al Ministerio Público para su investigación, plenamente identificado la persona y registrado el arma".

- Mayor Francisco Rubio Masa, Comisario PNP del Distrito de Nueva Cajamar-ca: "Tenemos conocimiento que ellos usan armas escopetas, en su territorio, es imposible ingresar a su territorio, no tenemos tipo de escopetas registradas, salvo las del comité de autodefensa. ...Ellos creen que la justicia ordinaria no puede intervenir, de acuerdo al código procesal penal, deben ser tratados por la justicia ordinaria"

- Dr. Julio Heber Santos Góngora; Fiscal Provincial Penal Corporativo de Nueva Cajamarca: "Son pocos los casos de tenencia ilegal de armas, solo se conoce un caso, de un nativo procesado e investigado por tenencia ilegal de armas de fuego...En caso de 
tenencia ilegal de arma de fuego, debe ser competencia de la justicia ordinaria; pero debo considerar que los nativos no utilizan otro tipo de arma de fuego, aparte de la escopeta con fines ce caza y de subsistencia. Aún en este caso, deben cumplir con la licencia del arma ante el organismo correspondiente.

- Dra. Juana Aylin Quezada Hidalgo, Directora Distrital de la Defensa Pública de San Martín: “...Si tenemos un caso en Nueva Cajamarca, en el que la defensa Pública ha designado al defensor público en asuntos indígenas para atender este caso. .. La tenencia ilegal de armas de fuego, no debe considerarse un delito dentro del territorio de las comunidades, porque ellos usan dicha arma con fines de caza y subsistencia, no lo tienen para otros fines. En caso de intervenirse, no debe ser tratado por la justicia ordinaria"

- Dr. Diego Montenegro Muguerza, Presidente de la Corte Superior de Moyo-bamba: "Si efectivamente. No hace mucho tiempo atrás respecto a los delitos que cometía los miembros de las comunidades nativas y rondas campesinas era el de condenar por el uso de dichas armas de fuego...en los últimos tiempos ese criterio ha cambiado, porque se ha entendido que el uso de las armas de fuego es con fines de caza y de subsistencia y no para otros fines..."

“...Sobre tenencia ilegal de armas, acá en nuestro distrito judicial han existido varios procesos contra comuneros nativos, por haberlos encontrado en su domicilio armas que ellos utilizan con fines de caza para su alimentación"

Muchos de ellos se han absuelto; existen comuneros y ronderos que vienen cumpliendo condena por este tipo de delito. En nuestro país la justicia comunal no sanciona el delito grave, yo creo que más adelante deben resolver los delitos graves cometidos en el su territorio.

Pregunta 5: ¿Por qué cree usted que los comuneros Awajún incurren en el delito de tenencia ilegal de armas de fuego?

Sobre este aspecto todos los entrevistados coinciden en que el problema radica en que los comuneros desconocen las leyes y normas del Código Penal que penalizan la tenencia ilegal de armas de fuego, que por tradición y cultura por lo general los utilizan con fines de subsistencia, caza y seguridad.

Pregunta 6: ¿Cree usted que el delito de tenencia ilegal de armas en el caso de nativos Awajún deben ser resueltos en la justicia ordinaria?

- Elsa Peas Cahuaza, Jueza de Paz No Letrada y Lenin Samash Kawaza, Gobernador del Distrito de Awajun, coinciden en manifestar: “... Estos casos deben ser resueltos en la comunidad, especialmente si se trata de tenencia de escopetas, porque los pobladores usan 
este tipo de armas para cazar animalitos. En caso de que fuera otro tipo de armas, si debe ser tratado en la policía y fiscalía"

- Lenin Samash Kawaza, recalca: “...debe ser resuelto en las dos instancias, debe consultarse a los Jefes de las comunidades...La Justicia comunal, es más justa y rápida. La Justicia ordinaria a veces comete errores. Lo que pasa es que nosotros no tenemos cárceles"

- Segundo Campos Huamán Comisario PNP (e) de Naranjos (Distrito Pardo Miguel): "...Si, cuando se trate de otro tipo de armas"

- Mayor Francisco Rubio Masa, Comisario PNP del Distrito de Nueva Cajamar-ca: "Debe aplicarse la justicia ordinaria; la ley de tenencia ilegal de armas, en ningún párrafo dice, que están exceptos los comuneros nativos. En caso de faltas los nativos deben recurrir el Juez de Paz no Letrado"

- Dr. Julio Heber Santos Góngora; Fiscal Provincial Penal Corporativo de Nueva Cajamarca: “...Creo que la justicia comunal debe resolver los casos de delitos civiles y faltas más no así los delitos penales, que deben ser resueltos por la justicia ordinaria"

- Dra. Juana Aylin Quezada Hidalgo, Directora Distrital de la Defensa Publica de San Martín: “...No... esos casos deben resolverlo la justicia comunal”

- Dr, Diego Montenegro Muguerza, Presidente de la Corte Superior de Moyo-bamba: “...El criterio que se usa para absolver el caso de nativos con tenencia de armas de fuego es el de error culturalmente condicionado que está consagrado en el Art. 15 del Código Penal, en este caso el comunero no tiene conocimiento, desconoce que tener un arma de fuego es contrario a la ley penal"

“...Como repito de acuerdo al Art. 149 de la Constitución, yo entiendo que ellos tienen todo tipo de competencias para conocer los delitos leves y graves, ahora que se viene dando mayor impulso a la justicia comunal desde la Corte Superior de Justicia"

Pregunta 7: ¿Consideras a la justicia comunal competente para juzgar los casos de tenencia ilegal de armas?

- Elsa Peas Cahuaza, Jueza de Paz No Letrada y Lenin Samash Kawaza, Gobernador del Distrito de Awajun, mencionan: "Si, los comuneros usan las escopetas para obtener sus alimentos..."

“...Lo que pasa es que se desconocen las Leyes, las armas se usan para la caza; no se registran su uso en asaltos... El problema se da cuando los comuneros compran armas de segunda; no se conoce la procedencia, ello puede acarrear problemas"

- Segundo Campos Huamán Comisario PNP (e) de Naranjos (Distrito Pardo Miguel): “...Es por el desconocimiento, hay un desconocimiento total por parte de ellos. Como le decía, ellos usan escopetas y retrocargas para la caza" 
- Mayor Francisco Rubio Masa, Comisario PNP del Distrito de Nueva Cajamarca: "No, debe aplicarse las leyes del Código Penal y de Tenencia ilegal de armas de fuego".

- Dr. Julio Heber Santos Góngora; Fiscal Provincial Penal Corporativo de Nueva Cajamarca: “...El tema de tenencia ilegal de armas, no creo que sea de competencia de la justicia ordinaria; porque los nativos, sólo usan armas, escopetas con fines de caza, como fuente de alimentación, no o usan con fines ilícitos, pero de todas mane-ras deben tenerla licencia para su uso.

- Dra. Juana Aylin Quezada Hidalgo, Directora Distrital de la Defensa Publica de San Martín: Si, lo creo...

- Dr. Diego Montenegro Muguerza, Presidente de la Corte Superior de Moyo-bamba: “...Plenamente de acuerdo la justicia comunitaria o especial tiene competencia para resolver los conflictos que se presentan al interior del territorio de la comunidad no solo deben resolver delitos menores sino también los mayores"

“...En cuanto a la eficacia de la justicia comunitaria, no hay ninguna duda... por-que los problemas o conflictos en las comunidades nativas son resueltas prontamente en una asamblea comunal, lo que no ocurre en la justicia ordinaria, tanto que tenemos leyes procesales que establecen plazos que muchas veces no se resuelven prontamente"

Pregunta 8: ¿Crees que las comunidades nativas deben contar con un registro sobre las armas de fuego hechizas?

- Elsa Peas Cahuaza, Jueza de Paz No Letrada y Lenin Samash Kawaza, Gobernador del Distrito de Awajun, coinciden en manifestar " $\mathrm{Si}$, creo que los jefes de las comunidades podrían tener un registro de armas especialmente si se trata de escopetas..."

".. Se podría implementar una coordinación con el organismo responsable y las comunidades para el registro de armas. Los Jefes de comunidad conocen a los moradores. Se recomendaría no comprar armas de segunda"

- Segundo Campos Huamán Comisario PNP (e) de Naranjos (Distrito Pardo Miguel): “...Por supuesto sería ideal, lo ideal sería que las autoridades comunales se reúnan y hagan un padrón de los moradores que posean armas de fuego".

- Mayor Francisco Rubio Masa, Comisario PNP del Distrito de Nueva Cajamarca: "No puede, el registro de armas y licencia debe hacerlo la Superintendencia Nacional de Control de Servicios de Seguridad, Armas, Municiones, y Explosivos de Uso Civil (SUCAMEC) “

- Dr. Julio Heber Santos Góngora; Fiscal Provincial Penal Corporativo de Nueva Cajamarca: "Sobre el registro y licencia de armas, debe hacerse bajo los organismos competentes para ello, como son 
- Dra. Juana Aylin Quezada Hidalgo, Directora Distrital de la Defensa Publica de San Martín: “...No creo que las comunidades nativas registren las armas de fuego ante el SUCAMEC, ellos deben resolver sus conflictos de acuerdo a sus costumbre y leyes. En caso de que utilicen dichas armas para otros fines.

- Dr, Diego Montenegro Muguerza, Presidente de la Corte Superior de Moyobamba: “...Me parece que la justicia especial tiene todas las facultades partas establecer registros de las armas de fuego, para evitar que sean juzgados por la justicia ordinaria"

Pregunta 9: ¿Qué recomendaciones haría Ud. para resolver los conflictos entre la justicia ordinaria y la justicia especial con respecto a la tenencia ilegal de armas de fuego?

- Elsa Peas Cahuaza, Jueza de Paz No Letrada del Distrito de Awajún: "La justicia ordinaria debe actuar en coordinación con los jefes de las comunidades y debe respetarse el protocolo aprobado por la Corte Superior de Justicia"

- Lenin Samash Kawaza, Gobernador del Distrito de Awajun: "En este caso recomendaría a las autoridades de la justicia ordinaria, conocer la cultura y la antropología, así como la realidad social de las comunidades. Porque si no podemos llegar a nivel de lo que ocurrió entre el Inca y Pizarro. Estoy de acuerdo con la creación del Consejo Mayor de justicia Comunal".

- Segundo Campos Huamán Comisario PNP (e) de Naranjos (Distrito Pardo Miguel): “...Lo ideal sería que las autoridades que imparten la justicia, capaciten y orientes a los comuneros. Los comuneros son personas accesibles, a veces hay un rompimiento, pero al final llegamos a un entendimiento. Ellos nos piden apoyo. Tenemos muy buena relación con los jefes y las comunidades nativas".

- Mayor Francisco Rubio Masa, Comisario PNP del Distrito de Nueva Cajamarca: "Indudablemente hay fallas en la coordinación, pero es necesario hacer entender a los comuneros que la ley es única, si la ley de da independencia en su organización, pero no en la administración de justicia. Es necesario formar equipos especia-les para capacitar a los comuneros, si ellos actúan así es por la falta de conocimientos"

- Dr. Julio Heber Santos Góngora; Fiscal Provincial Penal Corporativo de Nueva Cajamarca: “...Así como el Estado les ha dado a las comunidades nativas, grandes concesiones de terreno, a veces hacen tala indiscriminada o entregan las tierras en arrendamiento. El Estado debe acercarse a las comunidades nativas y campesinas, deben tener el apoyo y capacitación para la aplicación de la justicia comunal dentro de su autonomía; pero dentro de los límites señalados por la Ley y la Constitución”

- Dra. Juana Aylin Quezada Hidalgo, Directora Distrital de la Defensa Publica de San Martín: "Para resolver los conflictos entre la justicia ordinaria y la justicia comunal es 
que, los funcionarios del MP, PJ y PNP deben informarse, investigar el caso, coordinando y preguntando a los jefes de las comunidades nativas, si quieren la intervención de la justicia ordinaria"

"Sobre la constitución del Consejo Mayor de Justicia comunal, nosotros respaldamos y defendemos los derechos de los nativos y abogamos porque se respeten sus leyes y costumbres. Las comunidades nativas tienen respaldo constitucional para la jurisdicción de la justicia comunal dentro de su territorio... No debería de presentarse conflictos, si los hay, es por falta de capacitación en el tema de justicia intercultural."

“...El problema del protocolo, es que muchos funcionarios del Ministerio Público y del Poder Judicial se muestran reacios para aplicarlo. Esto se debe también al cambio constante de jueces y fiscales. Eso hace que se pierda a los capacitados".

- Dr., Diego Montenegro Muguerza, Presidente de la Corte Superior de Moyobamba: “...Yo recomendaría tanto a la justicia ordinaria que está a cargo del Poder judicial y la justicia comunal se establezcan mecanismos de articulación y coordinación debemos tocar estos remas para que se realicen talleres de capacitación a magistrados, fiscales y PNP, para que este tipo de delitos y conflictos se conozcan con un mayor dominio de la materia tanto en la justicia ordinaria y se conozcan... la justicia comunal en su territorio, tal como lo señala el Art. 149 de la Constitución Política. Felicito a los estudiantes y docentes de la UNSM-T, por estar investigando estos temas, que aún es desconocido en la región San Martín.

\subsection{Análisis del Exp. $\mathbf{N}^{\circ}$ 005-2014-PE-JUNC / Exp. $\mathbf{N}^{\circ}$ 100-2013-02- 2208-JR- PE}

El Exp. N $^{\circ}$ 005-2014-PE-JUNC / Exp. $\quad$ N $^{\circ}$ 100-2013-02- 2208-JR-PE, trata sobre el caso A1, procesado por el delito contra la seguridad pública, peligro común en la modalidad de tenencia ilegal de arma de fuego, donde el Ministerio Público a través de la Resolución $\mathrm{N}^{\circ}$ Tres, Nueva Cajamarca, Catorce de enero de 2014. Dicta auto de enjuiciamiento en contra de A1; como AUTOR del delito contra la Seguridad Pública-Peligro Común en la modalidad Tenencia ilegal de armas de fuego delito previsto en el artículo 279 del Código Penal, en agravio del Estado Peruano-Ministerio del Interior, imponiéndosele una pena de cuatro años de pena privativa de libertad y al pago de una Reparación Civil de setecientos nuevos soles (S/. 700.00).

De la declaración ofrecida por A1 el 19 de setiembre de 2012, en la comisaria PNP-Naranjos ante el instructor SO2 PNP, D1 el representante del Ministerio Público Dr. K1 (Fiscal adjunta de la 2da. Fiscalía Provincial Penal Corporativa de Nueva Cajamarca) se desprende que: El imputado dijo desconocer los motivos por el que fue detenido; toda vez que él, sólo estaba cumpliendo con una comisión encargada por el Apu de la Comunidad, desconociendo el término "daño". 
Declarante diga: ¿Precise si usted tiene conocimiento que portar armas de fuego sin la respectiva autorización constituye delito de tenencia ilegal de armas de fuego, penado por el código penal vigente?: Dijo; “...que, la verdad desconozco, ya que en mi comunidad siempre acostumbramos a tener armas de fuego hechizas y no tenemos licencia, es nuestra costumbre y por eso hemos ido a reparar estas armas sin conocer que nos iban a detener y que es un delito".

Declarante diga: ¿Para qué fines utilizan las armas de fuego $\mathrm{n}$ la comunidad nativa de Shampuyacu?: Dijo; “...que las armas son utilizadas específicamente para la caza de animales para nuestra sobrevivencia y para fines de resguardo en nuestra comunidad de Shampuyacu esto debido a nuestras costumbres".

Declarante diga: ¿Tiene algo más que agregar, quitar o modificar a la presente declaración: Dijo; “...Yo soy inocente del delito de tenencia ilegal de armas de fuego, ya que dichas armas están malogradas y además pertenecen a la comunidad nativa de Shampuyacu?

Las declaraciones de A1, confirman las respuestas vertidas por los pobladores y Apus de las comunidades Awajun encuestados y entrevistados ; así como el Informe del Ministerio de Justicia y Derechos Humanos en el que se reporta 49 casos entre sentenciados, procesados, archivados e investigados de los cuales dos corresponden al delito de tenencia ilegal de armas de fuego.

En este caso la defensa pública, solicita el sobreseimiento del caso sosteniendo que:

"Sr. Juez teniendo en cuenta que el acusado pertenece a una Comunidad Nativa, conforme lo ha manifestado el representante del Ministerio Público, mi patrocinado estaba llevando las armas por orden de la autoridad de la comunidad nativa, que llevaba las armas para que las reparen, que hay que ver las costumbres de dicha comunidad, que mi patrocinado tenía dieciocho años de edad, la defensa solicita el sobreseimiento de oficio con respecto de lo que acabo de oralizar, porque se trata de costumbres. Con respecto a los medios probatorios no me opongo a ningún me-dio de prueba...".

Ante lo cual el FISCAL indica: "Sr. Juez con respecto al sobreseimiento existen suficientes elementos de convicción o para proceder a juicio oral y dilucidar en el juicio la responsabilidad del acusado, por lo que solicito se declare infundado el sobreseimiento,"

\subsection{Discusión}

Explicar el origen y las causas de la colisión entre la justicia comunal y la justicia ordinaria es necesario recurrir a los antecedentes históricos, sociológicos, ideológicos y políticos sobre la génesis y desarrollo del derecho positivo y el derecho indígena en el Perú. 
Los estudios de Marzal, Irigoyen, Peña, Hurtado, Bramont y otros autores indican que históricamente se ha producido en una primera etapa una lucha irreconciliable entre el sistema político de dominación europea y el derecho de los pueblos indígenas; el cual se ve sometido a la aplicación de un enfoque monocultural y monista del Derecho.

Es a partir del Código Penal de 1924 en el que por primera vez se toma en cuenta las diferencias etnoculturales de la población peruana y la realidad multicultural del país, estableciendo un tratamiento jurídico-penal diferenciado al indígena, a quienes se calificaba como "salvajes" sin vínculo con la civilización. Es decir, se imponía el castigo al indígena no por sus actos, sino por quién era; era el ser indio lo que en ver-dad se castigaba. (Martínez, 2007).

Francia (1993), desde una posición más radical, hace una crítica severa al etnocentrismo jurídico expresada en el Código Penal de 1924 sobre la superioridad de la sociedad occidental sobre los demás y la califica de "una política etnocida y violatoria del derecho a la autonomía cultural, a la diferencia e identidad cultural". Hurtado, discrepa con las propuestas autonomistas de Francia, por considerarlas inviables.

El pluralismo y las propuestas de coordinación e integración jurídica, expuestas en el Código Penal de 1991; constituyen un gran avance en referencia al CP de 1924; en el que según Zaffaroni la referencia al tratamiento penal del indígena, tiene su origen en el Proyecto de Livingston para Lousiana en las que se les reconoce: "Las tribus indias que residían dentro de los límites de ese Estado se gobiernan por sus propias costumbres".

Es la política internacional, los acuerdos y convenciones de los estados expresados en la Declaración Universal de los Derechos Humanos, El Pacto Internacional de Derechos Civiles y Políticos, la Organización de los Estados Americanos, el Convenio 169 de la OIT, La Comisión Interamericana de Derechos Humanos, La Declaración Universal de los Derechos de los pueblos indígenas; la que afianza y desarrolla el nuevo paradigma jurídico intercultural.

En nuestro país, el avance y cambio rotundo se expresa en la constitución política de 1979 y la de 1993; que en su art. 2 inciso 19, proclama que toda persona tiene derecho a su identidad cultural. El Estado reconoce y protege la pluralidad étnica y cultural de la Nación; la cual es reforzada por el Art. 149 y ratificada por el art. 15 del Código Penal sobre el error de comprensión culturalmente condicionado como causa de inculpabilidad.

La jurisprudencia internacional (Argentina) resalta dos casos de aplicación de la justicia comunal: los casos F1 y J2. El primero por el delito de lesiones graves, (herida por disparo de arma de fuego). El segundo caso tratado por la Suprema Corte de Justicia de Salta fue por el delito de 
abuso sexual en perjuicio de una menor, pertenecientes al pueblo indígena Mapuche y Wichí respectivamente.

En el caso F1 de la comunidad Mapuche; este fue tratado en primera instancia por la justicia comunal con la presencia de ambas familias se resolvió, acordándose que la familia A debería entregar a la familia B el $25 \%$ del total de sus animales en compensación por el daño. Por lo que el caso se resolvía según la justicia Mapuche. Sin embargo, A aconsejado por el cacique de la comunidad, concurrió a la comisaría de Zapala para entregar el arma y los elementos sustraídos a la víctima, lo que provocó el inicio de la acción pública; y un tiempo después, B se presentó como querellante particular y actor civil buscando obtener un resarcimiento indemnizatorio". De esta manera, la intervención de la justicia indígena se ve disminuida y distorsionada.

En el caso J2, sentenciado en primera instancia; la defensa recurre a casación alegando que el fallo vulnera normas constitucionales al no respetar las costumbres y normas imperantes en el pueblo Wichí. Los magistrados de la Corte Resuelven declarar fundada la demanda de casación absolviéndose al imputado por considerar que el hecho se desarrolló en el contexto de convivencia del imputado y de la víctima en un marco de costumbre ancestrales y los Arts. 75 inc. 17 de la C.N. y 15 de la Constitución Provincial que garantizan el respeto a la identidad de los pueblos indígenas.

Por su parte la disidencia sostiene: que de acuerdo a lo mencionado en el Convenio 169, la costumbre invocada basada en el derecho consuetudinario Wichí no sólo resulta contradictoria con nuestro sistema jurídico nacional sino con el plexo de derechos humanos internacionalmente reconocidos y viola los derechos del niño. Por lo que falla rechazando el recurso de casación.

A nivel nacional Francia (2008) e Yrigoyen seleccionan sentencias que hacen referencia a casos en que la administración de justicia ordinaria del Perú tuvo que mediar con delitos cometidos por pobladores de origen indígena entre las que tenemos:

El Exp. No 97-0061 - 191601 - SP - 01, Exp. No 98-175, (Sala Penal de Loreto 1999, la Inst. Nº. 98-00320-010104JP01- (Distrito Judicial de Amazonas), el Exp. № 00-0492-191601-SP03/EXP. 492-00-Distrito Judicial de Loreto. En cuyos casos los magistrados se pronuncian amparando a los acusados en base a lo normado en el art 15 del código penal sobre error culturalmente, en algunos casos se aplica parcialmente, con eximentes reduciendo las penas.

En la región San Martín, Yrigoyen al estudiar la sentencia de la Corte Suprema del Perú del 09 de junio de 2004 sobre la absolución de los ronderos de Moyobamba por los delitos de secuestro y otros, señala que: "Esta sentencia es muy importante por-que sienta una interpretación progresiva en varios puntos controvertidos del artículo 149 de la Constitución de 1993, que reconoce la jurisdicción especial, la Corte Suprema se pone a la altura de los avances en el 
pluralismo en la región y abre paso a lo que puede ser el inicio de una «jurisprudencia pluralista» en el país. Esta sentencia supera la mentalidad monista que había marcado la mayor parte de decisiones judiciales en esta materia”. (Yrigoyen, 2006).

Del interrogatorio policial seguido a A1 y las respuestas vertidas por el comunero Awajún; permiten colegir que: El uso de las armas de fuego (escopeta) forma parte de la costumbre y tradición; el cual es utilizada como arma de caza para obtener sus alimentos, los comuneros no tienen conocimiento sobre la necesidad de registro, licencia y autorización del uso de armas, por lo mismo desconocen el tipo de delito penal cometido así como las sanciones establecidas en el código penal (art. 279 del CP y la Ley 30029); menos aún los alcances del Art. 15 del Código Penal referido al error culturalmente condicionado.

Los encuestados que respondieron y afirmaron conocer de casos denunciados ante la justicia ordinaria figura como el de mayor incidencia el de Asalto y robo con 61 casos que representa el $39,6 \%$, en segundo lugar el asesinato con 43 casos que representa el 27,9\%; en tercer lugar la violación, con 21,4\% que representa a 33: en cuarto lugar la tenencia ilegal de armas de fuego figuran con 22 casos representando el 14,2\%; la Agresión física con 6 casos, representando el $3,8 \%$, Conducción en estado de ebriedad se registran 2 casos que representan el 1,2\%; la tala ilegal e invasión a la propiedad, representan el 0,6\%; y en el rubro de otro no precisado por los encuestados aparecen 8 casos, representando el $5,1 \%$.

Asimismo, la declaración de los pobladores Awajún confirma que usan la retrocarga, escopeta o trampero en un porcentaje superior al $80 \%$, con fines de caza, subsistencia y seguridad; formando parte de su cultura y tradición incorporada por la por la cultura europea.

La tenencia ilegal de armas de fuego, materia de nuestro estudio registra un cuarto lugar con 22 casos. Registrándose también el caso de conducción en estado de ebriedad; por el uso frecuente de motocicletas lineales y trimóviles, facilitados por la red vial de carreteras que integran dichas comunidades.

Pese a que la mayoría de comuneros encuestados identifican las peleas y ataque entre comuneros como el problema de mayor incidencia seguida por el de hurto y robo, en tercer lugar, aparece un nuevo tipo de problema por ocupación de tierras con los colonos y en cuarto lugar aparece el asesinato. Al ubicar al problema con la PNP, la Fiscalía y el Poder Judicial como en los últimos lugares, se infiere que los casos en su mayoría se resuelven al interior de la comunidad. Destacándose la presencia de los casos de asesinato y conflictos por la ocupación de tierras, este fenómeno se hace recurrente en estos últimos años debido a que gran parte del territorio de las comunidades nativas Awajún se encuentras alquiladas a los colonos mestizos procedentes de otras regiones del país. 
Conforme a lo señalado por Zafaroni y Lesh; este tipo de delito sería un "error de prohibición" invencible... "es decir, cuando con la debida diligencia el sujeto no hubiese podido comprender la antijuricidad de su injusto, tiene el efecto de eliminar la culpabilidad. ... "Un error de prohibición está fundado cuando el autor a pesar del completo conocimiento de las circunstancias de las cuales resulta la realización de un tipo penal, no sabe que su acción es ilícita, por consiguiente, le falta solo la conciencia de la antijurídica". Los comuneros Awajun saben lo que hacen, tienen conciencia plena y están en pleno uso de sus facultades; pero no saben que la acción de portar un arma de fuego en sí constituye un delito.

Sobre el delito de peligro abstracto no existe unanimidad y convicción doctrinaria suficiente para que este delito este comprendido en el Código Penal; dogmáticos clásicos como Hippel, Binding y Beling y modernos como Zaffaroni y Bacigalupo, se oponen la inclusión de los delitos de peligro abstracto dentro de la legislación penal. Tal es así que Zaffaroni “con el pretexto de que vivimos en una sociedad de riesgos, se multiplican en el mundo los tipos de peligro que adelantan el momento consumativo a etapas muy previas a la lesión”. Por su parte Bacigalupo (1999), “en estos delitos no solo se debe comprobar la realización de una acción que supere los límites del peligro permitido. Además, se requiere que la acción haya representado un peligro para un determinado bien jurídico".

En este aspecto con relación a la tipificación como delito a la tenencia ilegal de armas de fuego, los comuneros, Apus Awajún, La Directora de la Defensa Pública y El Presidente de la Corte Superior de Justicia de San Martín; coinciden en señalar que este tipo no constituye delito dentro de la comunidad nativa Awajún. Si esto fuera así, entonces se estaría presentando una vaguedad e imprecisión en el Código Penal y en la Ley 30229; que podría mencionarse la excepción de ella a las armas de fuego utilizadas por los pobladores Awajún con fines de caza, subsistencia y seguridad en el ámbito de su territorio; los cuales podrían ser registradas por las propias comunidades en coordinación con el ente responsable el SUCAMEC.

Por su parte von Hippel, Binding y Beling citados por Bacigalupo (1999) en referencia a esta objeción indican: la peligrosidad de la acción "se presupone como motivo establecido por el legislador" juris et de jure. Esta presunción al no permitir que se realice un juicio de valoración respecto de la peligrosidad de la acción en el caso particular, nos pone frente a la duda respecto de si ésta no es una arbitrariedad, ya que parece ser más una regla de conducta u obediencia a la ley por el solo hecho de obedecer, aunque ningún bien jurídico se encuentre en peligro de ser dañado.

Al respecto dice von Hippel (19) "la sanción de verdaderas desobediencias puras, que no contienen de ninguna manera una puesta en peligro de los bienes jurídicos sería un 
descarrilamiento del legislador". Por su parte Binding la puesta en peligro sería a menudo (...) difícil de probar, por lo cual el legislador vería siempre la existencia de peligro como acciones normalmente peligrosas.

Para Beling, tales delitos "carecen de toda existencia justificada", en su opinión habrá delito de peligro abstracto "cuando la ley penal sanciona una acción en virtud de peligro que ésta normalmente representa, incluso en el caso de que no haya sido peli-grosa in concreto, de tal manera que el juez, naturalmente, no necesita comprobar una puesta en peligro, e inclusive la clara prueba de la carencia de peligrosidad de la acción no excluirá la aplicación de la ley penal”. De lo expuesto concluye el citado autor, que los delitos de peligro abstracto no serían sino "tipos sin lesión y sin peligro".

En el caso de la interpretación del error culturalmente condicionado; los juristas pe-ruanos consideran que el art. 15 del C.P. presenta dos concepciones: El error culturalmente condicionado por causa de inimputabilidad y error culturalmente condicionado por causa de inculpabilidad.

Para Hurtado, Villavicencio y Trazegnies, el art.15 del CP, tiene relación con el art. 20.1 del CP relativo a la inimputabilidad, por lo que los nativos indígenas comprendidos en este tipo de delito deben ser eximidos de la pena, porque los imputados no pueden comportarse de acuerdo a los patrones culturales extraños. La similitud es que, "ambos regulan supuestos de inimputabilidad y no de error, y la diferencia es que para el primero dichas causas son las costumbres o la cultura, mientras que para el segundo lo es la anomalía psíquica, la alteración de conciencia o en la percepción”. (Meine, 2007).

Siguiendo a Meine (2007), esta dualidad en el trato de la imputabilidad genera un trato no igualitario para todos los casos de inimputabilidad, haciendo caer en saco roto la buena voluntad de reconocer la diversidad cultural. El "Código Penal peruano diferencia claramente entre error de prohibición e inimputabilidad" afirmando que: que el art. 15 del CP se encuentra vinculado al art 14 del CP,". Porque en ambos casos se exime de responsabilidad o se atenúa la pena, dependiendo de si el error sobre la ilicitud e invencible o vencible, o de si la capacidad para comprender es nula o se encuentra disminuida". Sin embargo, este defecto legal; puede llevar al magistrado a la ambigüedad entre la aplicación del art. 14 o el art. 15 del CP; generándose resoluciones desfavorables a imputados procedente de una comunidad nativa indígena.

Para el caso de este estudio; las autoridades entrevistadas consideran que el delito de tenencia ilegal de armas de fuego no debe ser considerado como tal para los miembros de las comunidades nativas; por aplicación taxativa del art. 15 del CP y de la concepción cultural y tradición de los comuneros Awajún. 
La puesta en vigencia del Protocolo de Coordinación y el plan piloto de justicia intercultural como el de San Martín, reduce los casos de procesos judiciales en el que la población indígena se ve incriminada y penalizada como lo expresa el Informe del Ministerio Público; y la declaración del Presidente de la Corte superior de Justicia la colisión persiste, por lo que el Ministerio de Justicia se ha visto obligado a convocar a un Pleno sobre la tenencia ilegal de armas de fuego.

Las comunidades nativas Awajún de Alto Mayo, organizadas en la FERIAAM, reunidos en el distrito de Awajún en el III Congreso del Pueblo Indígena Awajun, sobre justicia comunal; donde en una acto sólo precedente en Colombia aprobaron la constitución del Concejo Mayor de Justicia Comunal, como institución rectora del Derecho indígena con competencias y autonomía suficiente para tratar no sólo las lesiones y faltas leves sino también los casos graves de homicidio y otros, tal como lo señala Mariano Entsakua Sutam, (Presidente de la FERIAAM).

Todo esto demuestra que la justicia indígena en el Perú, no se queda con los brazos cruzados, sino que busca alcanzar los estándares más elevados de justicia plural, pretendiendo avanzar hasta la consecución de una justicia autónoma; que todavía no goza de la aceptación mayoritaria de juristas y doctrinarios, de lo que sí, no quepa la menor duda es que la obsoleta doctrina del monismo jurídico etnocentrista ha quedado atrás.

Los autores de la presente investigación compartimos con la propuesta del pueblo Awajún; pero la aplicación de la misma requiere la reforma de la constitución política, del Código Penal y la creación de nuevas leyes que normen y regulen el tratamiento de la justicia indígena; ello dependerá exclusivamente del avance propositivo y organizativo de las organizaciones indígenas en el Perú y porque no decirlo de la política del estado nacional.

\section{Conclusiones}

Que la colisión entre la justicia comunal y la justicia ordinaria en América Latina y el Perú, tienen como precedentes el pasado histórico de dominación colonial y a la cosmovisión etnocentrista de la cultura europea que consideró a la población indígena americana, como incivilizada; por ende, exenta de los derechos y justicia del que gozaba el europeo.

Estudios de Marzal, Irigoyen y Zaffaroni desde la antropología, la sociología y el Derecho coindicen en señalar que esta confrontación, tiene que ver con razones culturales, ideológicas y políticas del pasado; cuestionadas hoy por el enfoque de la plena vigencia de los derechos humanaos y las garantías constitucionales.

El reconocimiento del pluralismo jurídico y la vigencia del derecho indígena en Latinoamérica y el Perú se desarrolla bajo el impulso de las políticas internacionales como: La Declaración 
Universal de los Derechos Humanos, La Organización de los estados americanos (1948), El Convenio 169 de la OIT (1968), El Pacto Internacional de los derechos civiles y políticos (1966), La Convención americana sobre derechos humanos (1966), La Declaración de las Naciones Unidas sobre los derechos de los pueblos indígenas (2007), la Corte Interamericana de los Derechos Humanos (1966).

La Constitución Política, reconoce la jurisdicción indígena, asimismo; el Código Penal; en el afán de regular el conflicto entre el derecho indígena y la justicia formal instituye el art. 15: el error culturalmente condicionado. La aplicación de este art. ha generado controversias en el sentido de que este precepto se encontraría regulado en el art. 20.1 por el argumento de que ambos regularían supuestos de inimputabilidad y no de error; la diferencia es que para el primero, dichas causas son las costumbres o la cultura mientras que para el segundo lo es la anomalía psíquica, la alteración de conciencia o en la percepción.

La legislación colombiana establece la inimputabilidad por diversidad cultural. El art. 33 del CP establece: «es inimputable quien en el momento de ejecutar la conducta típica y antijurídica no tuviere la capacidad de comprender su ilicitud o de determinarse de acuerdo con esa comprensión, por inmadurez sicológica, trastorno mental, diversidad sociocultural o estados similares». En tal sentido la inimputabilidad no se deriva de una incapacidad sino de una cosmovisión diferente y que, en los casos de error de prohibición invencible proveniente de tal diversidad cultural, el sujeto debe ser absuelto y no declarado inimputable. El art. 15 es eximente.

La otra confusión generada en la aplicación inadecuada del art. 14 del CP como si fuera el art. 15 "error culturalmente condicionado"; hecho presentado en las sentencias de los magistrados en casos seguidos a imputados indígenas que siguiendo el artículo 14, segundo párrafo del Código Penal referido a que: «el error invencible sobre la ilicitud del hecho constitutivo de la infracción penal, excluye la responsabilidad. Si el error fuera vencible se atenuará la pena». Optando a fallar atenuando la pena en vez de eximirla tal como ocurrió en el caso de los Ronderos de Moyobamba, en el que en la Corte superior dictaminó "pena privativa de libertad y pago de reparación civil"; razón por la cual la defensa recurrió a la Corte Superior la que falló absolviendo y archivando el caso.

Para Zaffaroni y otros observan el carácter subjetivo del delito contra la seguridad publica en su modalidad de tenencia ilegal de armas de fuego, tipificada en el art. 279 del Código Penal y la doctrina del derecho penal; consideran este delito como de peli-gro abstracto; por lo que debe ser revisado. 
En el caso de la opinión de los pobladores y jefes de las comunidades nativas Awajún, coinciden con el Presidente de la Corte Superior de Justicia de San Martín y la Directora de la Defensa Publica; para quienes este delito no debe alcanzar a los indígenas de las comunidades nativas.

Los resultados de la encuesta aplicada a los pobladores Awajún y del análisis del caso A1; este tipo no constituye delito; porque el uso de la escopeta, retrocarga o trampero forma parte de su tradición y costumbre, generalmente es utilizada con fines de caza y subsistencia.

Que, la motivación y criterio de un sector de autoridades, como lo mostrado en las entrevistas a la PNP y Fiscal en lo Penal; sobre el sesgo por la justicia ordinaria; tiene como sustento en la persistencia de la cosmovisión etnocentrista y el enfoque ideológico-político antes que en bases legales.

Que, la modernización e integración de los pueblos indígenas al proceso globalizador; ha dado surgimiento a nuevos problemas y conflictos como los señalados por los Jefes de las Comunidades nativas en lo relativo al arrendamiento de tierras, violación sexual, secuestro y otros.

Los comuneros, consideran a la justicia ordinaria proclive a dar sanciones en muchos casos para ellos "injustas" o contradictorias con la justicia indígena por ejemplo en el castigo por adulterio, que en el caso de la justicia ordinaria no es delito. Igual-mente, en la sanción castigo a los menores de edad; que la justicia oficial considera lesiva a la violación de los derechos del niño. Los Jefes de las comunidades nativas consideran que los castigos y penas impuestas por la justicia ordinaria no resuelven el problema ni corrige la conducta delictiva, como lo hace la justicia comunal.

Que, con el fin de contribuir con el control, y registro de armas de fuego; los Jefes y pobladores consideran oportuno la creación de un registro y padrón de los comuneros propietario de dichas armas y de producirse la intervención de la PNP, está debe actuar en coordinación con los Jefes de las Comunidades, y de esta manera evitar costos innecesarios a la familia del intervenido.

La creación del Concejo Mayor de Justicia Comunal de las comunidades nativas Awajún, constituye un hecho sin precedentes en el iter de la justicia comunal peruana; porque se estaría pasando hacia la instauración de una justicia indígena autónoma, con competencias para resolver no sólo los casos leves sino también los casos graves de violación, homicidio y asesinato, superando la etapa de la coordinación del derecho plural e integracionista.

Que, los resultados de la encuesta, muestran una acusación mutua entre ambos tipos de justicia: Los nativos señalando como responsables de la ausencia de coordinación a las autoridades policiales y judiciales del MP, y estos últimos responsabilizando a los Jefes y Apus de las Comunidades nativas. Esto se resolvería a través de la creación de una institución autónoma de justicia indígena. 


\section{Agradecimientos}

A las autoridades del Poder Judicial, Ministerio Público y Policía Nacional del Perú, por su colaboración y la predisposición mostrada en la grabación y filmación de las entrevistas.

A los pobladores de las comunidades nativas Awajun, que nos facilitaron el desarrollo de las encuestas, a los Apus, al Presidente de la FERIAAM, al Alcalde de la municipalidad distrital de Awajun, a la Jueza de Paz y al Gobernador distrital.

A los estudiantes, de la Facultad de Derecho de la UNSM por su desempeño en el trabajo de campo desarrollado en las comunidades nativas Awajun.

A la universidad Nacional de San Martín por el financiamiento al Proyecto de investigación en el marco del concurso de proyectos de investigación financiados con fondos del tesoro público.

Que debe continuarse con la implementación de la oralidad de los procesos de alimentos, tanto de fijación de pensión de alimentos como de las demás modalidades, para lograr que la oralidad sea aplicada a los demás procesos de derecho civil y derecho laborales que se ventilan en el Segundo Juzgado de Paz Letrado de Tarapoto.

\section{Referencias bibliográficas}

Ariza Santamaría, R. (2010). Coordinación entre sistemas jurídicos y administración de justicia indígena en Colombia. [Instituto Interamericano de Derechos Humanos]. www.iidh.ed.cr

Berdugo Gómez de la Torre, I. (1993). Reflexiones sobre la problemática del bien jurídico en Temas de Derecho Penal, $1^{\text {a }}$ ed. [Lima - Perú].

Burgos, D., Gabutti, G., Gómez Perdiguero, J., Merino, G. \& Valentina Scerbo, P. (2003).

Facultades Jurisdiccionales de las Comunidades Aborígenes en Materia Penal.

Bustos Ramírez, M. (1986). Manual de Derecho Penal. Editorial Ariel.

Calvo Suarez, D. G. (2009). Error de prohibición. Pleno Jurisdiccional Regional Penal. Poder Judicial. Actualidad Jurídica.

Castañeda Segovia, M. G. (2014). Tenencia ilegal de armas. Jurista Editores.

Castro Pozo, H. (1924). Nuestra comunidad indígena. El Lucero.

Chunga Hidalgo \& Peña Jumpa, A. (1998) Justicia Comunal en los Andes del Perú. El Caso de Calahuyo. Fondo Editorial de la PUCP, Lima.

De Trazegnies, F. (1993). Pluralismo jurídico: posibilidades, necesidades y límites. Secretaría de la OMPI.

Favre, H. (1991). Comunidades Campesinas y Nativas, en el nuevo contexto nacional. CAAAPSER.

Guevara Gil, A. (1998). La antropología del Derecho en el Perú: una disciplina marginal y 
periférica. [Instituto Indigenista Interamericano].

Hurtado Pozo, J. (1987) Manual de derecho penal. EDDILI.

Instituto Interamericano de Derechos Humanos. (2010). Coordinación entre sistemas jurídicos y administración de justicia indígena en Colombia.

Ley de Comunidades Nativas y de Desarrollo Agrario de la Selva y de Ceja de Selva. (1978). Art. $8^{\circ}$. [Perú].

Ley N²29785. (2011). Ley de Consulta Previa. [Perú].

Luis. (1993). Pluralidad cultural y derecho penal. Revista de Derecho, 47.

Martínez Huaman, R. E. (2009). Insuficiencia del artículo 15 del Código Penal ¿Error de comprensión culturalmente condicionado?. [Pleno Jurisdiccional Regional Penal. Poder Judicial].

Meini, I. (2007) Inimputabilidad penal por diversidad cultural sobre el artículo 15 del Código Penal. Revistas. PUCP. http://revistas.pucp.edu.pe/

Ministerio de Justicia. (2011). Protocolo de Atención y Orientación Legal con Enfoque Intercultural.

Nessier, F. E. (2013). El delito de peligro abstracto. Límites a su legislación. [Universidad Católica de Santa Fe].

Nuevo Código Procesal Penal. (2013). Decreto Legislativo $N^{\circ}$ 957. Jurista Editores.

OIT. (1989). Organización Internacional del Trabajo.

ONU. (2009). Declaración de las Naciones Unidas sobre los derechos de los pueblos indígenas.

Ortiz, L. \& Neiser Luis. (2009). Jurisdicción ordinaria y jurisdicciones especiales. Revista Electrónica del Trabajador Judicial.

Poder Judicial. (2014). Protocolo de coordinación entre sistemas de justicia.

Ruiz Chiriboga, O. \& Donoso, G. (2007). Pueblos Indígenas y la Corte Interamericana: Fondo y Reparaciones.

Ruíz Molleda, J. C. (2012). Análisis de la jurisdicción comunal en el Plan CERIAJUS.

Schiavo, N. (2010). La tenencia y portación de armas de fuego. [Buenos Aires, Argentina].

Tobin, B. (2008). El Derecho consuetudinario en el acceso y la participación en los beneficios y la gobernanza de los CC.TT.: Perspectivas desde los países andinos y los países insulares del Pacífico, elaborado en colaboración entre la ONU y la OMPI.

Ugaz Heudebert, J. D. (2009). La eximente de "obediencia debida” en el Derecho Penal peruano. [Pontificia Universidad Catolica del Perú].

UNAM. (1994). La teoría general del derecho frente al derecho indígena. Crítica jurídica. Revista Latinoamericana de política, filosofía y Derecho, 14.

Villavicencio Terreros, Fe. A. (2011). Tratamiento penal de la diversidad cultural por la justicia estatal. 
Vol. 1, Núm. 2, jul-dic, 2021

Yrigoyen Fajardo, R. (2000). Tratamiento judicial de la diversidad cultural y la jurisdicción especial en el Perú.

\section{Conflicto de intereses}

El autor indica que no existen conflictos de interés.

\section{Copyright (c) 2021 Lionel Bardales del Aguila}

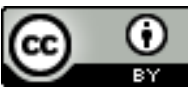

Este texto está protegido por una licencia CreativeCommons 4.0.

Usted es libre para Compartir — copiar y redistribuir el material en cualquier medio o formato- y Adaptar el documento — remezclar, transformar y crear a partir del material— para cualquier propósito, incluso para fines comerciales, siempre que cumpla la condición de:

Atribución: Usted debe dar crédito a la obra original de manera adecuada, proporcionar un enlace a la licencia, e indicar si se han realizado cambios. Puede hacerlo en cualquier forma razonable, pero no de forma tal que sugiera que tiene el apoyo del licenciante o lo recibe por el uso que hace de la obra.

Resumendelicencia - Textocompletodelalicencia

Citar como: Bardales del Aguila, L. (2021). La colisión entre la justicia comunal y la justicia ordinaria, en el delito de tenencia ilegal de armas de fuego en la etnia Awajún. Revista Científica Ratio Iure, 1(2), 4-37. https://doi.org/10.51252/rcsi.v1i2.195 